\title{
NEW NON-DESTRUCTIVE INSPECTION METHOD WITH GROUND PENETRATING RADAR TO EVALUATE THE SUITABILITY OF THE BACKFILLING GROUTING INJECTION IN TUNNEL BORING MACHINES
}

\author{
Catalina Mondragon-Enguidanos ${ }^{1}$, Amparo Verdu Vazquez ${ }^{2}$, Jose Luis \\ Hernández-Álvarez ${ }^{3}$, Jorge Gomez-Hoyos ${ }^{1}$, and Luis A. Méndez-Lanza ${ }^{1}$ \\ ${ }^{1}$ Acciona \\ ${ }^{2}$ Universidad Politecnica de Madrid \\ ${ }^{3}$ ACCIONA Engineering
}

October 26, 2020

\begin{abstract}
This research focuses on the development of a new non-destructive inspection method, based on the interpretation of electromagnetic waves by means of a ground penetrating radar (GPR), in order to evaluate the condition of the backfilling two-component mortar grouting behind the segmental lining in tunnels made by tunnel boring machines (TBM). The data processing by digital models and the analysis of the propagation speed of the along the backfilling grouting layer have enabled the technical and operational feasibility of this novel inspection method. Once the conceptual framework of the research was defined, it was possible to validate the developed method in a full-scale operational environment in the Metro of Quito Line 1 (Ecuador). This validation involved a battery of tests collating the results obtained through the core-drilling extractions in comparison with the ones obtained with GPR. As a result of these calibration tests, it was possible to identify a range of propagation speeds linked to grouting in optimal execution conditions, as well as other ranges associated with potential anomalies. Finally, it was possible to implement this new inspection methodology on a regular basis in the Metro of Quito, where the conventional quality control by core-drillings was replaced almost entirely for the new method with GPR.
\end{abstract}

\section{Hosted file}

Manuscript sin.pdf available at https://authorea.com/users/370315/articles/488997-new-nondestructive-inspection-method-with-ground-penetrating-radar-to-evaluate-the-suitabilityof-the-backfilling-grouting-injection-in-tunnel-boring-machines 

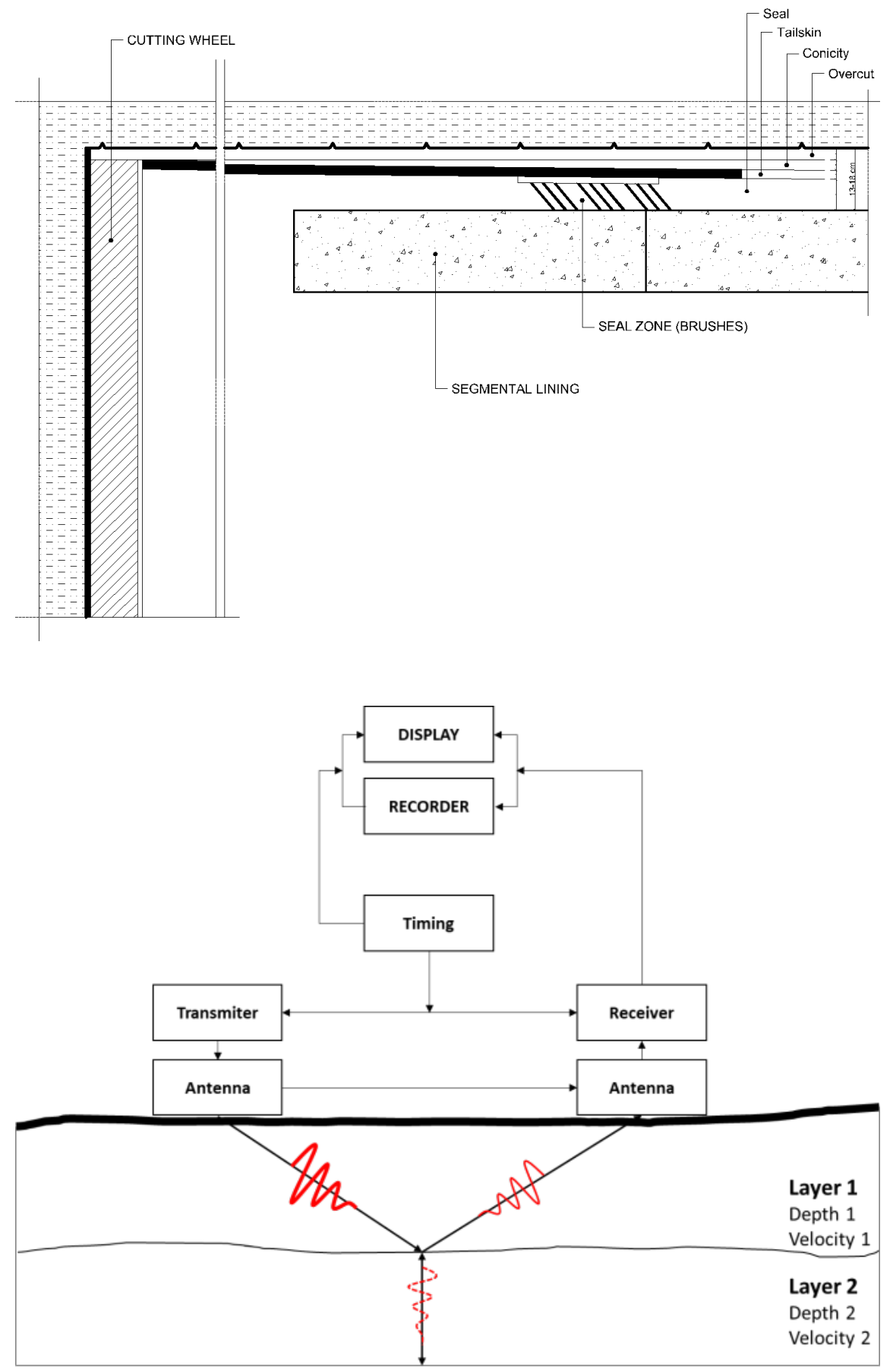

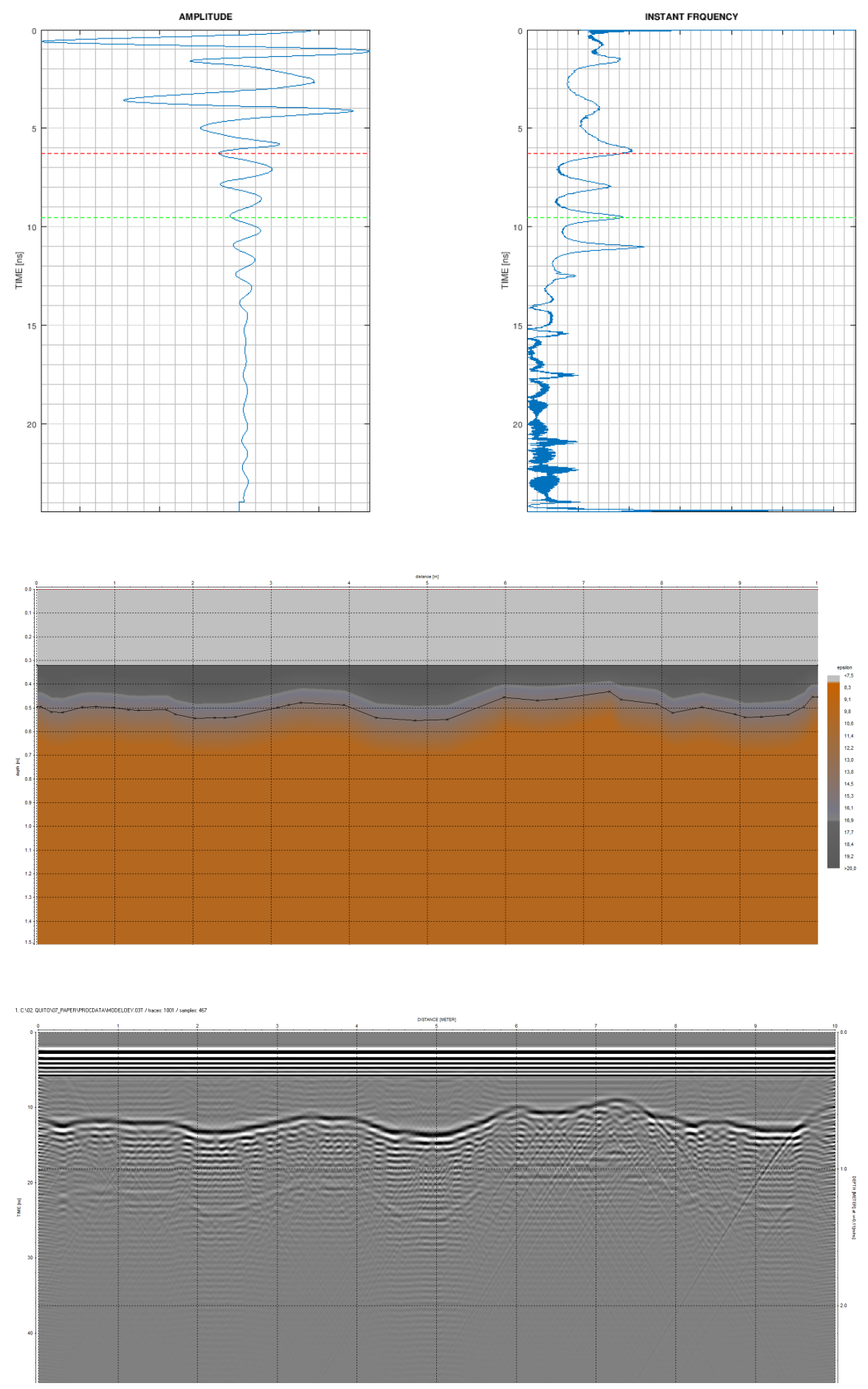

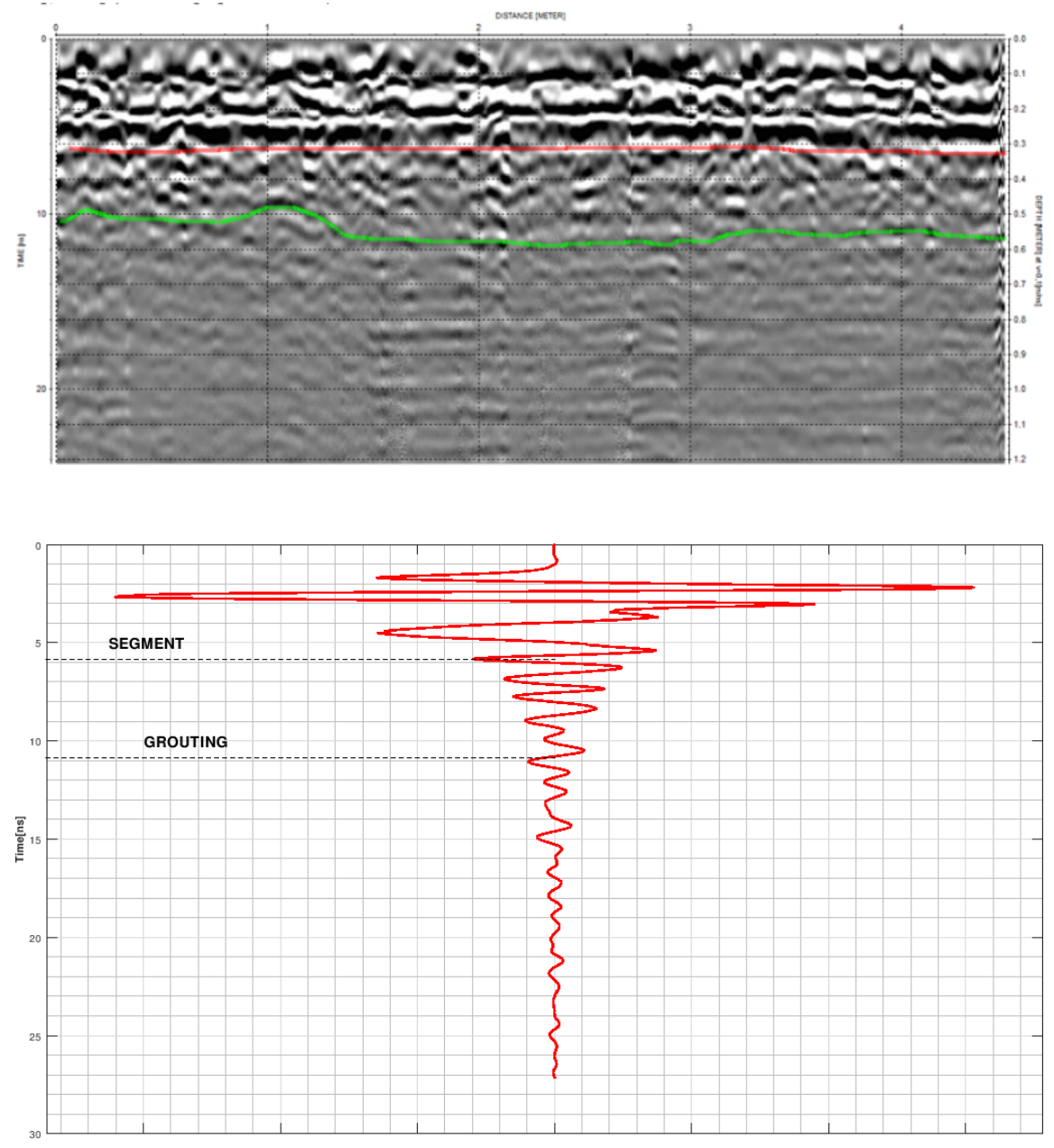

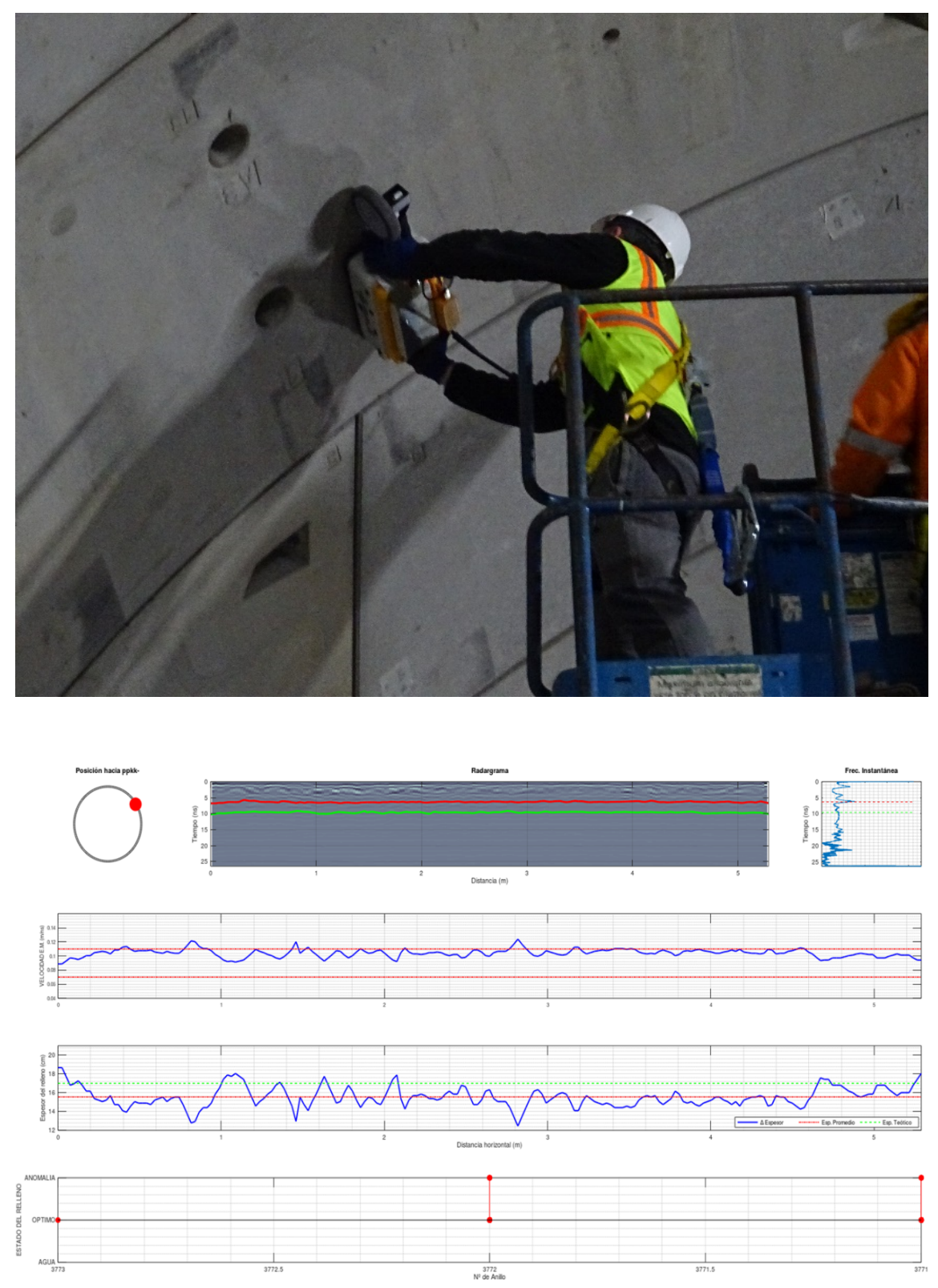

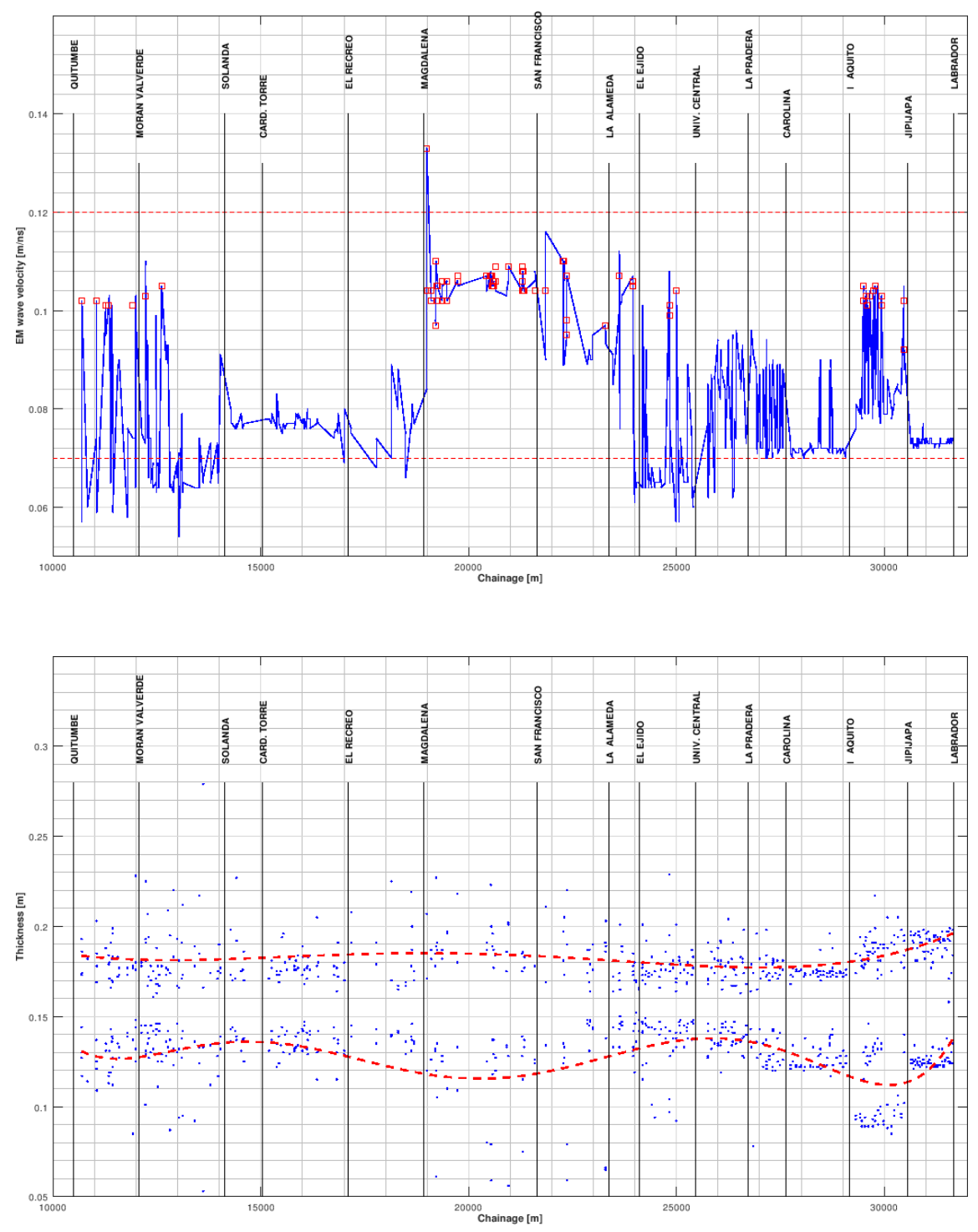